of the University of Pretoria, and Dr. J. Murray, South African Institute for Medical Research. Gordon STJVEN

Department of Botany,

University of the Witwatersrand, Johannesburg. April 15.

\section{Microbiological Decomposition of Malto- and Lacto-bionate}

Stodola and Lockwood ${ }^{1}$, and Kluyver, De Ley and Rijven ${ }^{2}$, demonstrated that several species of Pseudomonas are able to oxidize maltose and lactose to the corresponding malto- and lacto-bionic acid, by oxidation of the reducing group of the disaccharide, without breaking the oxygen bridge. Some strains of Pseudomonas consume the calcium salt of these acids slowly ${ }^{2}$. Pseudomonas is a common surface inhabitant of several natural waters, so it is likely that under these natural conditions these cells may convert maltose from polysaccharides (formation of lactose is improbable) into the corresponding acid. It seemed to be of interest to ascertain what kind of microorganisms are endowed with the ability to consume maltobionate, with the view of getting an idea of the importance of this decomposition process in Nature. Lactobionate was included in view of a future study of the enzymatic mechanism of its breakdown.

Petri dishes, containing agar, with potassium, ammonium and magnesium sulphates, yeast extract, calcium carbonate and a calcium bionate, were inoculated with ditch- and river-water, stagnant water, soil, humus, dune-sand, etc., and incubated, usually at $25^{\circ}-30^{\circ} \mathrm{C}$., one set aerobically, another anaerobically. Growth in anaerobic conditions was scanty, and only a few colonies developed on bionates. On the other hand, there was a luxurious aerobic growth on bionates and a great variety of microflora developed. Of these, more than sixty strains have been isolated and investigated. These strains quickly consume maltoor lacto-bionate, or both, in a liquid culture medium when incubated for plentiful aeration in a shaking device in an incubator room at their optimal temperature. The consumption of bionates was determined by the titrimetric method of Kluyver, De Ley and Rijven $^{2}$. The accompanying list indicates the bacteria found (nomenclature according to "Bergey", 6th edit. ; quantitative data will be published elsewhere) : Escherichia freundii or intermedium ; Paracolobactrum aerogenozdes; Aerobacter aerogenes; Aerobacter cloaca ; Serratia plymuthicum; Alcaligenes facalis ; Achromobacter sp.; Flavobacterium sp.; Corynebacterium simplex and helvolum; Pseudomonas quorescens and sp.; Bacillus megatherium and circulans. Several other bacteria, as yet unidentified, are able to consume malto- and/or lacto-bionate. Usually several different strains of the same microorganism were isolated. $E$. coli strains are unable to consume maltobionate; some decompose lactobionate slowly. Most of the above-mentioned strains decompose both bionates. Only maltobionate can be broken down under anaerobic conditions by some strains of Aerobacter. The following moulds decompose maltobionate: Penicillium sp.; Hormodendrum cladosporoüdes; Aspergillus sp.; Fusarium merismoüdes, avenaceum and oxysporum. It is remarkable that no yeasts were detected.
Most of the bacteria grow well on the corresponding disaccharide. Some of the apparent exceptions are under investigation.

The following scheme of maltose decomposition in natural surface waters is proposed, this being additional to those already known:

Maltose
Maltobionate
obligate aerobic micro-organisms
Glucose and gluconate
or
unidentified pathway.

The large number of strains observed suggests that this pathway for the metabolism of maltose may be quite important in Nature.

A full account of these and related results will be published elsewhere. We also hope to publish a preliminary investigation of the enzymatic mechanism in the near future. We are indebted to Sandoz, Ltd. (Switzerland), for a generous gift of lactobionate. M. BERNAERTS

Central Laboratory,

Ministry of Economic Affairs, Brussels.

Biochemical Lakoratory,

Veterinary College,

State University, Ghent. April 12.

I Stodola, F., and Lockwood, L., J. Biol. Chem., 171, 213 (1947).

'Gluyver, A. J., De Jey, J., and Rijven, A., Ant. v. Leeuwenhook J. Microb. Serol., 17, 1 (1951).

\section{Deoxyribonucleic Acid Content of} Haploid and Diploid Aspergillus Conidia

In 1948, Boivin, Vendrely and Vendrely ${ }^{1}$ suggested that the somatic nuclei of a vertebrate species may contain a fixed amount of deoxyribonucleic acid that is double the amount present in the germ cells. Since then, a considerable volume of evidence has been obtained to support this view ${ }^{23}$. Some apparent exceptions, such as rat liver, have been found, but these can be explained by the presence of nuclei with different degrees of 'ploidy'. The evidence is consistent with the view that in resting nuclei a specific amount of deoxyribonucleic acid is associated with each set of chromosomes ${ }^{4}$.

In vertebrate tissues it is difficult to make sure that a tissue has a population of nuclei homogeneous in respect of the number of chromosome sets. Therefore we have thought it of use to investigate the deoxyribonucleic acid content of conidia of diploid and haploid strains of Aspergillus nidulans ${ }^{5}$. These conidia are uninucleate; genetic and cytological evidence shows that in different strains the nuclei are either diploid or haploid, and in the conidia the nuclei are all uniformly in one stage, presumably the resting stage. The volumes of the diploid and haploid conidia are ${ }^{5,6}$ in the ratio of $2: 1$.

Two haploid strains were used: the wild type ( + , green conidia) and a mutant strain $\left(w_{a}\right)$ with white conidia?. Two diploid strains heterozygous for known markers were prepared ${ }^{5}$ : one with green conidia $\left(w_{a}\right.$ lys $\left./ a d_{2} y\right)$ and the other with white conidia $(28-a)$. The latter strain was obtained through somatic recombination ${ }^{6,8}$ from a green diploid $\left(w_{n} p_{a b a_{1}} b i_{1} / a d_{2} y\right)$. Cultures were grown on a minimal agar medium containing glucose and mineral 